\title{
Ecofisiologia da germinação de sementes de Campomanesia pubescens
}

\author{
Ecophysiology of Campomanesia pubescens seed germination
}

\section{Sara Dousseau ${ }^{* *}$ Amauri Alves de Alvarenga $^{\mathrm{I}}$ Renato Mendes Guimarães ${ }^{\mathrm{II}}$ Túlio Silva Lara ${ }^{\mathrm{I}}$ Telde Natel Custódio ${ }^{I I}$ Izabel de Souza Chaves ${ }^{\mathrm{I}}$}

\section{RESUMO}

\begin{abstract}
A gabiroba de arbusto [Campomanesia pubescens (DC.) O. Berg. (Myrtaceae)], espécie nativa do Cerrado é considerada uma planta com potencial melífero, ornamental e medicinal. Com o objetivo de avaliar a influência de diferentes temperaturas, substratos e condições de luminosidade e da secagem, na qualidade fisiológica de suas sementes foram conduzidos dois experimentos. No primeiro utilizou-se sementes com $13 \%$ de teor de água, o qual foi realizado em delineamento experimental inteiramente casualizado em esquema fatorial (4x3x2), composto por quatro temperaturas $\left(15-25,20-30^{\circ} \mathrm{C}\right.$ alternadas, 25 e $30^{\circ} \mathrm{C}$ constantes), três substratos (sobre papel, entre areia e entre vermiculita) e duas condições de luminosidade (claro e escuro) e, o segundo com sementes recém extraídas dos frutos e secas superficialmente, contendo $35 \%$ de teor de água e após a secagem em estufa com ventilação forçada de ar a temperatura de $30^{\circ} \mathrm{C}$ por 30,60 , $90,120,150,180,260,360,750$ e 810 minutos. Para a avaliação da qualidade fisiológica de sementes de gabiroba de arbusto, a semeadura sobre papel, no escuro e a $30^{\circ} \mathrm{C}$ possibilita uma melhor expressão do vigor. As sementes de gabiroba de arbusto são intolerantes a secagem, podendo ser classificadas como recalcitrantes.
\end{abstract}

Palavras-chave: luz, temperatura, substrato, secagem.

\section{ABSTRACT}

The gabiroba bush [Campomanesia pubescens (DC.) O. Berg. (Myrtaceae)], a native species of the Cerrado is considered a plant with melliferous, ornamental and medicinal potential. Aiming to evaluate the influence of abiotic factors on seed germination, two experiments were conducted. The first was conducted in a completely randomized design in a factorial design $(4 \times 3 \times 2)$, composed of four temperatures (15- $25,20-30^{\circ} \mathrm{C}$ alternate, 25 and $30^{\circ} \mathrm{C}$ constant), 3 substrates (paper, sand and vermiculite) and two light conditions (light and dark). The second experiment aimed to evaluate the tolerance to desiccation of fresh seeds dried superficially, with $35 \%$ of water, by drying it in oven with forced ventilation of air at $30^{\circ} \mathrm{C}$ for $30,60,90,120,150,180,260,360,750$ and 810 minutes. To evaluate the physiological quality of seeds gabiroba, shrub planting on paper, in the dark and $30^{\circ} \mathrm{C}$, enables a better expression of the force. The seeds of bush gabiroba are intolerant to desiccation and can be classified as recalcitrant.

Key words: light, temperature, substrate, drying.

\section{INTRODUÇÃO}

Campomanesia pubescens (DC.) O. Berg. (Myrtaceae), conhecida como gabiroba de arbusto é uma espécie nativa do Brasil, encontrada amplamente no Cerrado das regiões Sudeste e Centro-Oeste, bem como em outros países da América do Sul, como a Argentina, Uruguai e Paraguai. A planta é considerada melífera e ornamental, pois no período de floração ocorre a desfolha e a mesma reveste-se inteiramente de delicadas flores brancas. O fruto é apreciado in natura, com propriedades levemente laxativas, podendo ser utilizado para a confecção de geléias, sorvetes, refrescos, doces, pudins, licores, batidas ou curtidos na cachaça. Devido ao pequeno porte pode ser cultivada em associação com outras fruteiras arbóreas, possibilitando maior produção de alimentos por área

'Setor de Fisiologia Vegetal, Departamento de Biologia, Universidade Federal de Lavras (UFLA), Campus Universitário, CP 3037, 37200-000, Lavras, MG, Brasil. E-mail: saradousseau@yahoo.com.br. *Autor para correspondência.

"Departamento de Fitotecnia, UFLA, Lavras, MG, Brasil 
(ALMEIDA et al., 1998). As folhas e cascas do caule são utilizadas na medicina popular na forma de decocto ou infusão, no combate a afecções do aparelho urinário e na diarréia, sendo conferida ação adstringente (RODRIGUES \& CARVALHO, 2001).

A germinação das sementes pode ser definida como a sequência de eventos fisiológicos que ocorrem antes da protrusão da raiz primária em sementes embebidas não dormentes, sendo a etapa que envolve o estabelecimento das plântulas, denominado de evento pós-germinativo (NONOGAKI, 2006). O processo germinativo é regulado por vários fatores ambientais, como umidade, oxigênio, temperatura, luz e nutrientes (SEO et al., 2009).

A sensibilidade das sementes à luz é dependente da ação do fitocromo e este altera a sua sensibilidade em função da temperatura (HESCHEL et al., 2007; FRANKLIN, 2009). Os fitocromos modulam níveis endógenos de giberelina (GA) e ácido abscísico (ABA), bem como a capacidade de resposta de giberelinas (SEO et al., 2009). A temperatura altera o potencial de crescimento do embrião, bem como influencia nos níveis hormonais (TOH et al., 2008; PENFIELD, 2008; YAMAGUCHI, 2008). Dessa forma há uma relação entre demanda por luz e temperatura (SEO et al., 2009).

O substrato é um fator complexo que influencia de diversas maneiras no processo germinativo e pós-germinativo, de forma que na escolha do material para substrato deve ser levado em consideração o tamanho da semente e sua exigência em relação à umidade e luz, considerando principalmente densidade, capacidade de absorção e retenção de água, aeração e drenagem, ausência de pragas, doenças e substâncias tóxicas, além de oferecer facilidade para a avaliação das plântulas (BRASIL, 2009).

O teor de água nas sementes é outro fator que influencia decisivamente no processo germinativo e na sua longevidade. Com relação à tolerância a secagem, as sementes podem ser classificadas em dois grandes grupos, ortodoxas e recalcitrantes. As sementes ortodoxas suportam a dessecação no final de seu amadurecimento na mãe planta e são capazes de manter seu potencial de germinação por longos períodos de armazenamento em estado seco. Por outro lado, as sementes recalcitrantes possuem elevado teor de água na maturidade, são intolerantes à dessecação e começam a germinar imediatamente após a fase de maturação, sem passar pela fase de secagem e quiescência metabólica. Vários trabalhos vêm sendo realizados para elucidar a eventual necessidade ou sensibilidade das sementes ao processo de dessecação, sendo de grande importância quantificar esse comportamento (MASETTO et al., 2008; FISHER, 2008; ANGELOVICI et al., 2010).

Devido a escassez de estudos referentes à germinação das sementes dessa espécie, e aliado a crescente demanda pela propagação de espécies medicinais do cerrado (DOUSSEAU et al., 2007; ZAIDAN \& CARREIRA, 2008) são necessários maiores esclarecimentos quanto aos fatores que influenciam no processo germinativo. Neste contexto objetivou-se avaliar a influência de diferentes temperaturas, substratos e condições de luminosidade e da secagem na qualidade fisiológica de sementes de gabiroba de arbusto.

\section{MATERIAL E MÉTODOS}

Os frutos foram coletados numa reserva particular de Cerrado em Ijaci - MG e levados para o laboratório de Crescimento e Desenvolvimento de Plantas da Universidade Federal de Lavras, onde permaneceram por 48 horas à temperatura ambiente para decomposição parcial da polpa, que foi em seguida retirada em água corrente com auxílio de uma peneira, enquanto que as sementes foram postas para secar por um período de 24 horas, em condições de laboratório. Antes da instalação do teste de germinação as sementes foram desinfestadas com Cercobin a $1 \%$ (pv), durante 5 minutos.

No experimento 1 , o comportamento germinativo foi avaliado distribuindo-se as sementes em diferentes substratos (sobre papel, entre areia e entre vermiculita) em caixas gerbox, submetidas a diferentes condições de luminosidade (claro e escuro) e temperaturas $\left(15-25,20-30^{\circ} \mathrm{C}\right.$ alternadas e 25 e $30^{\circ} \mathrm{C}$ constantes), utilizando-se um germinador tipo Biochemical Oxigen Demand (B.O.D.), com 58\% de UR e fotoperíodo de 12 horas. A condição do escuro foi obtida envolvendo-se as caixas gerbox em papel alumínio e sacos de polietileno preto, sendo o comportamento germinativo avaliado sob luz verde. A semeadura entre areia e vermiculita foi realizada a $0,5 \mathrm{~cm}$ de profundidade em caixas gerbox perfuradas, contendo $250 \mathrm{~mL}$ dos substratos. No substrato papel, as sementes foram dispostas sobre duas folhas de mata-borrão.

As avaliações foram realizadas diariamente para o teste de germinação, utilizando-se como critérios para o substrato papel, a protrusão de $2 \mathrm{~mm}$ (raiz primária mais hipocótilo), e para os demais, a visualização de qualquer estrutura (geralmente o "gancho" hipocotiledonar) na sua superfície. Para todos os substratos foram consideradas plântulas normais àquelas cujos cotilédones se libertavam facilmente do tegumento, tornando possível à visualização do 
meristema apical e sistema radicular, sem qualquer dano. Foram calculados a porcentagem de germinação, de plântulas normais, anormais e índice de velocidade de germinação(IVG), segundo MAGUIRE (1962).

O delineamento estatístico foi inteiramente casualizado em esquema fatorial $2 \times 3 \times 4$, em quatro repetições de 25 sementes/tratamento. A análise estatística foi realizada mediante o uso do programa estatístico Sisvar (FERREIRA, 1999) sendo realizada a análise de variância e as médias comparadas pelo teste de Tukey $(\mathrm{P}<0,05)$.

No experimento 2, para a avaliação da tolerância a dessecação, as sementes após o beneficiamento foram colocadas em uma estufa de ventilação regulada a $30^{\circ} \mathrm{C}$ por $30,60,90,120,150,180$, 260, 360, 750, 810 minutos, comparando-se com as sementes recém colhidas e secas superficialmente a $35 \%$ (umidade inicial). Durante a dessecação, a umidade desejada foi monitorada através de pesagens, por meio da equação descrita por CROMARTY et al. (1985). O teor de água foi determinado com base em massa úmida, utilizando-se o método padrão da estufa a $105 \pm 3^{\circ} \mathrm{C}$ por 24 horas (BRASIL, 2009), com três repetições de $1 \mathrm{~g}$. Após a dessecação, a qualidade fisiológica das sementes foi avaliada sobre o substrato papel mataborrão em B.O.D, regulado para manter a temperatura constante de $30^{\circ} \mathrm{C}$, no escuro, conforme critérios indicados para o experimento 1 . Os procedimentos estatísticos foram realizados conforme o primeiro experimento, sendo as médias submetidas à análise de regressão polinomial $(\mathrm{P}<0,05)$.

\section{RESULTADOS E DISCUSSÃO}

Não foi observada interação tripla para nenhuma variável estudada, sendo a porcentagem de germinação e o índice de velocidade de germinação influenciados pelos três fatores estudados (luz, temperatura e substrato), destacando-se a interação dupla entre os mesmos para o índice de velocidade de germinação.

A porcentagem de germinação foi superior a $90 \%$ e todas as sementes que emitiram a raiz primária se desenvolveram em plântulas normais e, aquelas que se desenvolveram no escuro tinham o mesmo aspecto, ou seja, de estiolamento. No escuro foi observada a maior porcentagem de germinação em relação à presença de luz (Figura 1A). O maior índice de velocidade de germinação também foi observado no escuro, em todas as temperaturas (Figura 1D) e substratos (Figura 1E). Dessa forma pode-se classificar as sementes de gabiroba de arbusto como fotoblásticas negativas.

De maneira diferente ao observado neste estudo, ZAIDAN \& CARREIRA (2008) relataram que o comportamento das sementes da maioria das espécies arbustivas do cerrado é fotoblástico positivo. SANTOS et al. (2004) observaram comportamento indiferente à luz no processo germinativo de sementes de Campomanesia xanthocarpa O. Berg., no entanto sementes com resposta fotoblástica negativa têm sido relatadas em algumas espécies, como Prangos ferulaceae (L.) Lindl (Apiaceae) (RAZAVI \& HAJIBOLAND, 2009).

O comportamento fotoblástico positivo está bem esclarecido na literatura, sendo aceito que a luz estimula a síntese de giberelina pela ação do fitocromo, bem como modula a capacidade de resposta a esse fitohormônio (YAMAGUCHI, 2008; SEO et al., 2009). Em sementes de Arabidopsis sensíveis a luz, a germinação no escuro não aconteceu por uma série de fatores, dentre eles um aumento nos níveis de ácido abscísico (SEO et al., 2009). No entanto, os mecanismos envolvidos na resposta fotoblástica negativa ainda não são compreendidos.

Uma das hipóteses pode estar relacionada com um excesso de giberelina endógena, pelo fato da sua produção ser estimulada na presença de luz. Em Coffea arabica cv. 'Rubi' (Rubiaceae), fotoblásticas negativas, a aplicação de giberelina inibiu a germinação, uma vez que causou a morte de células no embrião (SILVA et al., 2005). Dessa forma, quando essas sementes são postas para germinar no escuro mantêm teores mais adequados de giberelina endógena, favorecendo o sincronismo do processo, conforme observado para a gabiroba.

Com relação à influência do substrato, a maior porcentagem de germinação foi observada na areia e a menor na vermiculita, contudo, para o substrato sobre papel não houve diferença entre os demais tratamentos (Figura 1B). Para o índice de velocidade de germinação, o substrato interagiu com a luminosidade (Figura 1E) e com a temperatura (Figura 1F). No desdobramento da interação entre substrato e luz (Figura 1E) observou-se que o maior vigor, avaliado pelo índice de velocidade de germinação ocorreu quando se utilizou o papel, para ambas as condições de luminosidades. Em presença de luz, a areia foi o segundo melhor substrato, seguido da vermiculita, enquanto no escuro, a vermiculita foi superior a areia. Em todas as temperaturas a velocidade de germinação foi superior no substrato papel, seguido da vermiculita e areia, que estatisticamente não diferiram entre si (Figura 1F).

O aspecto das plântulas de gabiroba de arbusto foi distinto em função do substrato quando germinadas na presença de luz. Somente em presença de luz observou-se que as plântulas que se 


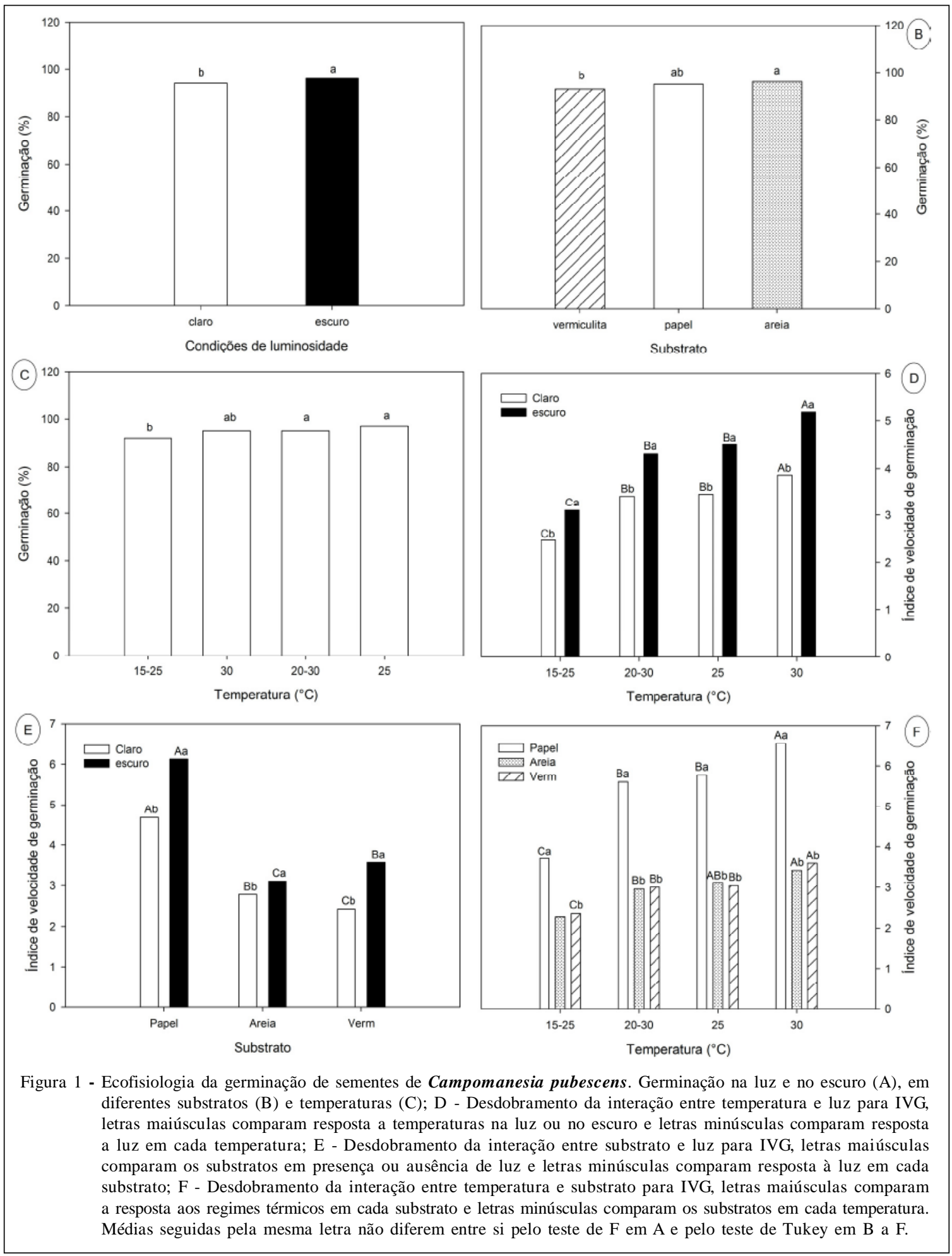

desenvolveram sobre papel tinham eixo hipocótiloradícula com menor comprimento e maior espessura e a radícula com ausência de ramificações. Provavelmente, a incidência de luz no sistema radicular provocou alterações no seu desenvolvimento.
Embora a vermiculita seja um substrato que possui boa retenção de umidade e alta porosidade, indicado para várias espécies, para a gabiroba de arbusto prejudicou a germinação. A areia tem maior capacidade de drenagem de água, mantendo o substrato 
com menor umidade, o que para muitas espécies é prejudicial, entretanto, para esta espécie favoreceu a germinação. Para Campomanesia phaea (Berg.) Landr., ao contrário do observado nesse estudo, o processo germinativo foi favorecido com a semeadura na vermiculita e no papel, sendo que o pior desempenho foi observado na areia (MALUF \& PISCIOTTANOEREIO, 2005).

Provavelmente, o melhor desempenho observado no papel seja devido à facilidade de visualização da protrusão radicular, conforme comentado anteriormente, quando se realiza a avaliação do teste de germinação em papel. Dessa forma, quando o objetivo do estudo for apenas a protrusão radicular para esta espécie deve-se realizar o teste de germinação no escuro e sobre papel.

Quanto à influência da temperatura podese verificar que independente da luminosidade e do substrato, a maior porcentagem de germinação ocorreu a 20-30 e $25^{\circ} \mathrm{C}$, não diferindo entre si, enquanto que a $15-25^{\circ} \mathrm{C}$ constatou-se a menor porcentagem (Figura $1 \mathrm{C}$ ), entretanto a $30^{\circ} \mathrm{C}$ não houve diferença das demais temperaturas. Para o índice de velocidade de germinação constatou-se interação entre temperatura e luminosidade (Figura 1D) e com o substrato (Figura 1F), cujo maior valor, tanto no claro quanto no escuro foi alcançado na temperatura de $30^{\circ} \mathrm{C}$, seguido de $20-30 \mathrm{e}$ $25^{\circ} \mathrm{C}$, que não diferiram entre si, enquanto que a 15 $25^{\circ} \mathrm{C}$ alternada foi observado o menor vigor (Figura 1D).

A temperatura ótima propicia uma porcentagem de germinação máxima em menor espaço de tempo (MAYER \& POLJAKOFF-MAYBER, 1979). As temperaturas máximas aumentam a velocidade de germinação, entretanto apenas as sementes mais vigorosas conseguem germinar, o que determina redução na porcentagem final de germinação. Por outro lado, temperaturas mínimas reduzem a velocidade de germinação e alteram a uniformidade de emergência, talvez ocasionado pela incidência de patógenos e pelo maior tempo de ação desses sobre a semente (CARVALHO \& NAKAGAWA, 2000). Assim, a combinação ideal para a avaliação da protrusão radicular de gabiroba é a $30^{\circ} \mathrm{C}$, no escuro e sobre papel.

As sementes de gabiroba de arbusto foram capazes de germinar sob todos os regimes térmicos avaliados (Figura 1). Para sementes de outras espécies do gênero Campomanesia também observou-se essa plasticidade térmica, conforme reportado por SANTOS et al. (2004), que trabalhando com C. xanthocarpa, a $15,20,25,30$ e $15-30^{\circ} \mathrm{C}$ com substrato entre areia observaram germinação superior a $90 \%$ em noventa dias. MALUF \& PISCIOTTANO-EREIO (2005) verificaram que a porcentagem de germinação de sementes de $\boldsymbol{C}$. phaea foi superior a 90\%, aos 60 dias, nos substratos sobre papel e vermiculita, nas temperaturas avaliadas $\left(25^{\circ} \mathrm{C}\right.$ e $\left.30^{\circ} \mathrm{C}\right)$. Segundo ZAIDAN \& CARREIRA (2008) a maioria das sementes das espécies do Cerrado germina entre 20 e $30^{\circ} \mathrm{C}$ e são indiferentes a luz. Temperaturas alternadas nem sempre favoreceram a germinação das sementes, no entanto, alteraram a sensibilidade à luz em algumas espécies (GODOI \& TAKAKI, 2004), enquanto que em outras não (SIMÃO \& TAKAKI, 2008). Para gabiroba de arbusto a resposta fotoblástica não foi alterada em função dos regimes térmicos testados.

No desdobramento da interação entre temperatura e substrato (Figura $1 \mathrm{~F}$ ) pode-se observar que o maior índice de velocidade de germinação ocorreu a $30^{\circ} \mathrm{C}$ e o menor a $15-25^{\circ} \mathrm{C}$, em todos os substratos. No papel e na areia a $20-30$ e $25^{\circ} \mathrm{C}$, a velocidade de germinação das sementes foi intermediária, não diferindo entre si. Na vermiculita apenas a $20-30^{\circ} \mathrm{C}$ os valores foram intermediários, enquanto que a $25^{\circ} \mathrm{C}$ a velocidade de germinação não diferiu das demais temperaturas.

Com relação a tolerância a dessecação podese observar que o teor de água das sementes de gabiroba de arbusto quando extraídas dos frutos foi de $42 \%$ (Figura 2A), o qual foi reduzindo exponencialmente em função da secagem, chegando a $4 \%$ de umidade aos 810 minutos. Após secagem por 60 minutos a germinação e o vigor das sementes com um teor de água de 35\% foram maior. Essa ligeira secagem inicial atua como um sinal para a passagem do estado de desenvolvimento para a germinação, sendo importante para sinalizar que está fora do fruto e pode iniciar o processo germinativo (CATUSSE et al., 2008; ANGELOVICI et al., 2010).

A qualidade fisiológica das sementes de gabiroba foi afetada pela dessecação a partir de $30 \%$ de umidade (Figura 2B-D), cujo decréscimo no teor de água de 35 para $4 \%$ acarretou em redução no potencial germinativo, no vigor e na porcentagem de plântulas normais, bem como aumento no número de plântulas anormais, levando a conclusão de se tratarem de sementes recalcitrantes, pois não toleram a redução do teor de água.

Para todas as variáveis verificou-se redução linear em função da secagem, porém com intensidades distintas, sendo que a porcentagem de protrusão radicular teve a redução menos intensa em relação às demais variáveis, com valores de $42 \%$ quando a umidade atingiu 4\% (Figura 2B). Quando a umidade foi de até $13 \%$ (360 minutos de secagem) todas as sementes que emitiram a raiz se desenvolveram em plântulas normais, no entanto, com a redução do teor de água para 5\%, aos 750 minutos de secagem houve apenas $8 \%$ de plântulas normais. Aos 810 minutos de secagem 


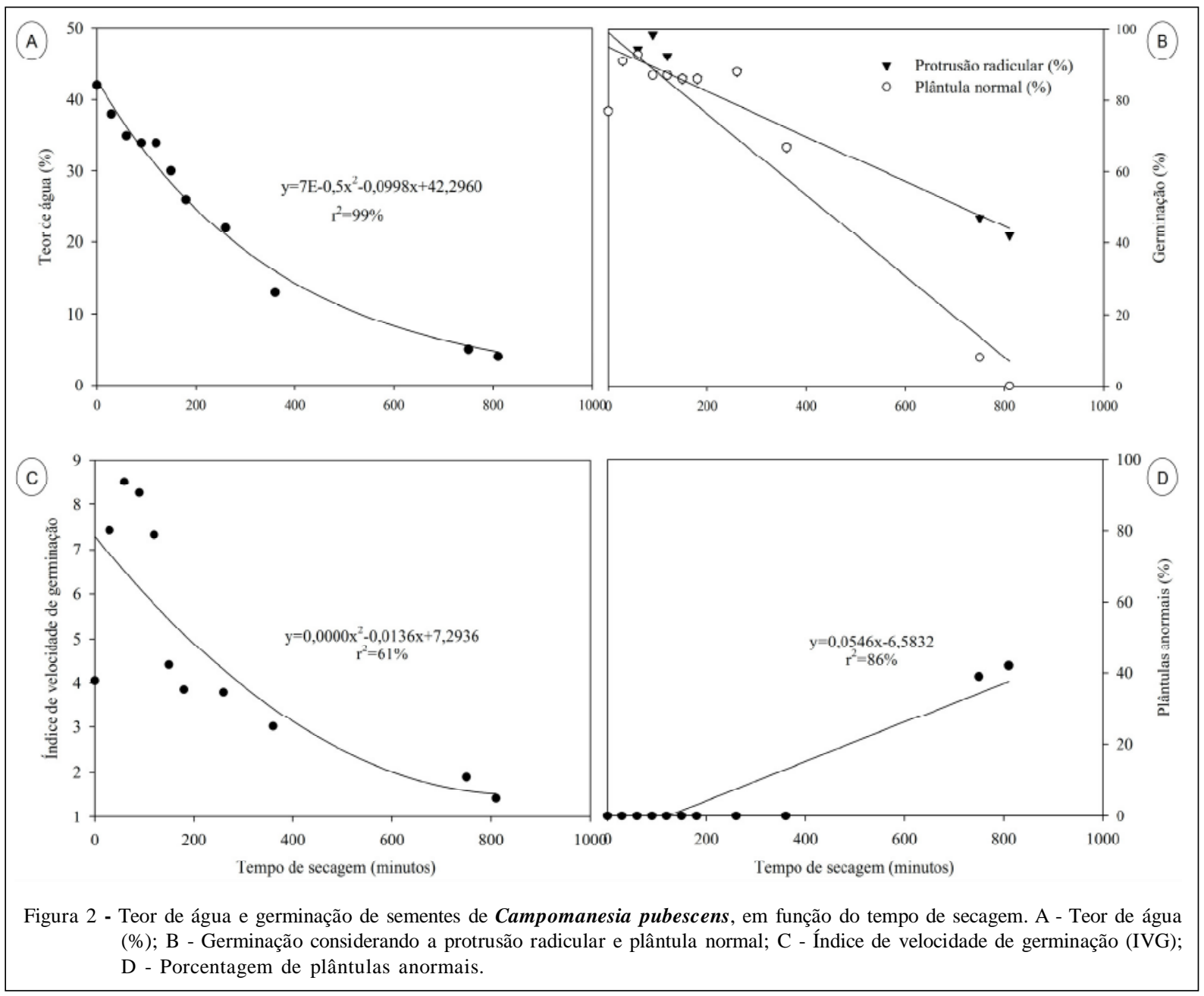

o teor de água foi $4 \%$ e a porcentagem de plântulas normais nula, pois a partir da secagem a $5 \%$ de umidade surgiram as plântulas anormais (Figura 2D). Quanto ao vigor houve um incremento com a secagem entre $60 \mathrm{e}$ 120 minutos e teor de água entre 35 e $34 \%$ (Figura 2C), pois valores inferiores a $30 \%$ de umidade acarretou em redução acentuada na velocidade de germinação.

Em sementes recalcitrantes diversos danos são observados com a secagem (FARIA et al., 2004; MASETTO et al., 2008), enquanto que nas ortodoxas diversos mecanismos são ativados para evitá-los (FISHER, 2008; ANGELOVICI et al., 2010).

A secagem superficial favorece a germinação, enquanto que a redução do teor de água de 35 para $4 \%$ acarreta em redução no potencial germinativo, vigor e na porcentagem de plântulas normais, aumentando o número de plântulas anormais.

\section{CONCLUSÃO}

Para testes de germinação e vigor de sementes de Campomanesia pubescens deve-se realizar a semeadura sobre papel, no escuro e a $30^{\circ} \mathrm{C}$. As sementes são intolerantes a secagem, sendo classificadas como recalcitrantes.

\section{AGRADECIMENTOS}

Ao Conselho Nacional de Desenvolvimento Científico e Tecnológico (CNPq) pela concessão das bolsas de mestrado (primeiro autor); produtividade em pesquisa (segundo autor) e iniciação científica (quarto e sexto autores).

\section{REFERÊNCIAS}

ALMEIDA, S.P. et al. Cerrado: espécies vegetais úteis. Planaltina: EMBRAPA-CPAC, 1998. 464p.

ANGELOVICI, R. et al. Seed desiccation: a bridge between maturation and germination. Trends in Plant Science, London, v.15, n.4, p.211-218, 2010. Disponível em: <http:// download.cell.com/trends/plant-science/pdf/ PIIS1360138510000063.pdf>. Acesso em: 8 nov. 2010. doi: 10.1016/j.tplants.2010.01.003.

BRASIL. Ministério da Agricultura, Pecuária e Abastecimento. Secretaria de Defesa Agropecuária. Regras para análise de sementes. Brasília: MAPA/ACS, 2009. 399p.

Ciência Rural, v.41, n.8, ago, 2011. 
CARVALHO, N.M.; NAKAGAWA, J. Sementes: ciência, tecnologia e produção. 4.ed. Jaboticabal: FUNEP, 2000. 588p.

CATUSSE, J. et al. Transcriptome- and proteome-wide analyses of seed germination. Comptes Rendus Biologies, Netherlands, v.331, n.10, p.815-822, 2008. Disponível em: $<\mathrm{ht} \mathrm{t}$ : : / / w w w. s c i e n c e d i r e ct. com/ science?_ob=MImg\&_imagekey=B 6 X1F-4TC8J4G-6$3 \&$ cdi $=7241$ \&_user $=686380$ \&_pii $=$ S $1631069108002035 \&$ origin $=$ search \& coverDate $=10 \% 2 \mathrm{~F} 31 \% 2 \mathrm{~F} 2008 \& \_s k=996689989 \&$ view $=c \& w c h p=d G L b V z b z S k z S \& m d 5=f 4 f 3 c 9 e b c e 61$ fa82be80df1 c3f $21 \mathrm{db} 56 \&$ ie $=/$ sdarticle.pdf $>$. Acesso em: 1 ago. 2010. doi: 10.1016/j.crvi.2008.07.023.

CROMARTY, A.S. et al. Design of seed storage facilities for genetic conservation. Rome: International Board of Plant Genetic Resources, 1985. 100p.

DOUSSEAU, S. et al. Superação de dormência em sementes de Zeyheria montana Mart. Ciência e Agrotecnologia, Lavras, v.31, n.6, p.1744-1748, 2007. Disponível em: <http:// www.scielo.br/pdf/cagro/v31n6/a21v31n6.pdf>. Acesso em: 3 set. 2008. doi: 10.1590/S1413-70542007000600021.

FARIA, J.M.R. et al. Desiccation sensitivity and cell cycle aspects in seeds of Inga vera subsp. affinis. Seed Science Research, Wallingford, v.14, n.2, p.165-178, 2004.

FERREIRA, D.F. Software SISVAR: Sistema de análises estatísticas. Versão 4.3. Lavras: UFLA, 1999. 1 CD.

FISHER, K.M. Bayesian reconstruction of ancestral expression of the lea gene families reveals propagule-derived desiccation tolerance in resurrection plants. American Journal of Botany, Lancaster, v.95, n.4, p.506-515, 2008. Disponível em: 〈http://www.amjbot.org/cgi/reprint/95/4/506>. Acesso em: 1 nov. 2010.

FRANKLIN, K.A. Light and temperature signal crosstalk in plant development. Current Opinion in Plant Biology, Amsterdam, v.12, n.1, p.63-68, 2009. Disponível em: <http://www.sciencedirect.com/ science?_ob=MImg\&_imagekey=B6VS4-4TRXDNY-1-5\&_cdi=6252 \&_user=686380\&_pii=S1369526608001635\&_origin=search\&_cover Date $=02 \% 2 F 28 \% 2 F 2009 \& \_s k=999879998 \&$ view $=c \& w c h p=d G L b V l$ W-zSkzV\&md5=91286811 c78b4acccda9a64249c3c1bd\&ie=/ sdarticle.pdf>. Acesso em: 1 jan. 2010. doi: 10.1016/j.pbi.2008.09.007.

GODOI, S.; TAKAKI, M. Effects of light and temperature on seed germination in Cecropia hololeuca Miq. (Cecropiaceae). Brazilian Archives of Biology and Technology, Curitiba, v.47, n.2, p.185-191, 2004. Disponível em: <http://www.scielo.br/ pdf/babt/v47n2/20565.pdf>. Acesso em: 13 nov. 2006.

HESCHEL, M. S. et al. A new role for phytochromes in temperature-dependent germination. New Phytologist, London, v.174, n.4, p.735-741, 2007. Disponível em: <http:/ /www.colora docollege.edu/dept/by/Faculty\&Staff/ShaneHeschel/ Heschel\%20et\%20a1\%20NewPhyt2007.pdf>. Acesso em: 16 fev. 2009.

MAGUIRE, J.D. Speed of germination-aid in selection and evaluation for seedling emergence and vigour. Crop Science, Madson, v.2, n.1, p.176-177, 1962.

MALUF, A.M.; PISCIOTTANO-EREIO, W.A. Secagem e armazenamento de sementes de cambuci. Pesquisa Agropecuária Brasileira, Brasília, v.40, n.7, p.707-714, 2005. Disponível em: <http://www.scielo.br/pdf/pab/v40n7/a12v40n7.pdf>. Acesso em: 13 nov. 2006

MASETTO,T.E. et al. Desiccation tolerance and DNA integrity in Eugenia pleurantha O. Berg. (Myrtaceae) seeds. Revista Brasileira de Sementes, Brasília, v.30, n.1, p.175-180, 2008. Disponível em: <http://www.scielo.br/pdf/rbs/v30n2/a07v30n2.pdf >. Acesso em: 1 nov. 2009. doi: 10.1590/S0101-31222008000200007.

MAYER A.M.; POLJAKOFF-MAYBER, A. The germination of seeds. 2.ed. Oxford: Pergamon, 1979. 192p.

NONOGAKI, H. Seed germination-the biochemical and molecular mechanisms. Breeding Science, Tokyo, v.56, n.2, p.93-105, 2006. Disponível em: <http://www.jstage.jst.go.jp/ articl e/jsbbs/56/2/93/_pdf>. Acesso em: 13 ago. 2008. doi: $10.1270 /$ jsbbs.56.93.

PENFIELD, S. Temperature perception and signal transduction in plants. New Phytologist, London, v.179, n.3, p.615-628, 2008. Disponível em: <http://onlinelibrary.wiley.com/doi/10. $1111 /$ j.1469-8137.2008.02478.x/pdf >. Acesso em: 23 jul. 2008. doi: $10.1111 / \mathrm{j} .1469-8137.2$ 008.02478.x.

RAZAVI, S.M.; HAJIBOLAND, R. Dormancy breaking and germination of Prangos ferulaceae seeds. EurAsian Journal of BioSciences, Konak-Izmir, v.3, n.11, p.78-83, 2009. Disponível em: <http://ejobios.com/pdf/EJOB-09-17-3,11,7883.pdf>. Acesso em: 11 ago. 2010.

RODRIGUES, V.E.G.; CARVALHO, D.A. Plantas medicinais no domínio dos cerrados. Viçosa: UFLA, 2001. 180p.

SANTOS, C.M.R. dos et al. Características de frutos e germinação de sementes de seis espécies de Myrtaceae nativas do rio grande do sul. Ciência Florestal, Santa Maria, v.14, n.2, p.13-20, 2004. Disponível em: <http://redalyc.uaemex.mx/ pdf/534/53414202.pdf>. Acesso em: 6 set. 2005.

SEO, M. et al. Interaction of light and hormone signals in germinating seeds. Plant Molecular Biology, Dordrecht, v.69, n.4, p.463-472, 2009. Disponível em: <http://www.spri ngerlink.com/content/c6qw136g4838u40w/fulltext.pdf $>$. Acesso em: 15 ago. 010. doi: 10.1007/s11103-008-9429-y.

SILVA, E.A.A. et al. Exogenous gibberellins inhibit coffee (Coffea arabica cv. 'Rubi') seed germination and cause cell death in the embryo. Journal of Experimental Botany, London, v.56, n.413, p.1029-1038, 2005. Disponível em: <http:// jxb.oxfordjournals.org/content/56/41 3/1029.full.pdf+html>. Acesso em: 4 ago. 2005. doi: 10.1093/jxb/eri096.

SIMÃO, E.; TAKAKI, M. Efeito da luz e da temperatura na germinação de sementes de Tibouchina mutabilis (Vell.) Cogn. (Melastomataceae). Biota Neotropica, Campinas, v.8, n.2, p.63-68, 2008. Disponível em: <http://www.scielo.br/pdf/bn/ v8n2/a06v8n2.pdf>. Acesso em: 1 nov. 2010. doi: 10.1590/ S1676-06032008000200006.

TOH, S. et al. High temperature-induced abscisic acid biosynthesis and its role in the inhibition of gibberellin action in Arabidopsis seeds. Plant Physiology, Rockville, v.146, n.3, p.1368-1385, 2008. Disponível em: <http://www.plantphysiol.org/cgi/reprint/ 146/3/136 8>. Acesso em: 2 ago. 2009. doi: 10.1104/ pp.107.113738.

YAMAGUCHI, S. Gibberellin metabolism and its regulation. Annual Review of Plant Biology, Palo Alto, v.59, n.1, p.225251, 2008. Disponível em: <http://www.annualreviews. org/ doi/pdf/10.1146/annurev.arplant.59.032607.092804>. Acesso em: 13 jan. 2009 . doi: 10. 1590/S1677-04202008000300002.

ZAIDAN, L.B.P.; CARREIRA, R.C. Seed germination in cerrado species. Brazilian journal of plant physiology, Pelotas, v.20, n.3, p.167-181, 2008. Disponível em: <http://www.scielo .br/pdf/bjpp/v20n3/a02v20n3.pdf $>$. Acesso em: 7 mar. 2009. doi: $10.1590 / \mathrm{S} 1677-04202008000300002$. 